\title{
sciendo
}

\section{Physical and Physiological Demands During Handball Matches in Male Adolescent Players}

\author{
by \\ Manuel Ortega-Becerra' ${ }^{1}$ Alexis Belloso-Vergara ${ }^{2}$, Fernando Pareja-Blanco $^{1}$
}

\begin{abstract}
This study aimed to describe the physical and physiological demands of adolescent handball players and compare movement analysis and exercise intensities between the first and second halves and between the different periods of the match. Fourteen adolescent handball players (age $15.7 \pm 0.8$ years, body mass: $65.6 \pm 3.4 \mathrm{~kg}$, body height: $169.5 \pm 3.9 \mathrm{~cm}$ ), played two friendly matches, in which no substitutions were made. The analysis was carried out with a Global Positioning System technology. The following physical variables were analyzed: Total distance covered (TD); distance covered at faster velocities than $18 \mathrm{~km} \cdot \mathrm{h}^{-1}\left(\mathrm{TDC}>18 \mathrm{~km} \cdot \mathrm{h}^{-1}\right)$; number of accelerations (Accel) and decelerations (Decel); number of accelerations and decelerations higher than $2.78 \mathrm{~m} \cdot \mathrm{s}^{-2}$ (Accel $>2.78 \mathrm{~m} \cdot \mathrm{s}^{-2}$ and Decel $\left.>2.78 \mathrm{~m} \cdot \mathrm{s}^{-2}\right)$; number of sprints (Sprints); accelerations interspersed with a maximum of $30 \mathrm{~s}$ between them (RAS $\leq 30 \mathrm{~s}$ ) and as a physiological variable the heart rate (HR) was examined. Significant differences $(p<0.01-p<0.001)$ between the first and the second half in all variables mentioned were observed, except in Accel $>2.78 \mathrm{~m} \cdot \mathrm{s}^{-2}$ and Decel $>2.78 \mathrm{~m} \cdot \mathrm{s}^{-2}$. This trend was also observed when comparing performance between the different 10-min periods. The 5 th period (period 40$50 \mathrm{~min}$ ) was the one that showed differences with respect to the previous ones. Adolescent handball players showed lower levels of exercise intensity, assessed by both time-motion and HR data, in the second half of matches, especially in the middle of this period.
\end{abstract}

Key words: Global Positioning System, total distance, accelerations, decelerations, sprint.

\section{Introduction}

Handball is a team sport characterized by intense, intermittent activities including running, sprinting, and jumping, as well as regular throwing, hitting, blocking, and pushing between players (Gorostiaga et al., 1999; Granados et al., 2008). During competition the work-rate intensity and volume of the external load are highly heterogeneous and players are exposed to both high- and low-level intensities of external loads (Corvino et al., 2014). Thus, identifying the sportspecific demands is a key factor to establish which variables are most important for the development of optimal handball training programs (OrtegaBecerra et al., 2018; Taylor et al., 2017).

The demands of competition in handball have usually been reported via time-motion analysis using video analysis methods (Chelly et al., 2011; Michalsik and Aagaard, 2015; Michalsik et al., 2013, 2014; Šbila et al., 2004). Although these methods are reliable, they are also timeconsuming, potentially variable, and unrealistic for real-time assessment or for comparison with other norms (Taylor et al., 2017). The Global Positioning System (GPS) technology has recently emerged as a useful and practical tool for quantifying the physical demands of players during training and competitive match-play in many outdoor sports (Arruda et al., 2015). However, a very small number of studies have used GPS technology to analyze handball demands. Corvino et al. (2014) used GPS technology to analyze the demands induced in small-sided games (SSG) in handball, whereas Barbero et al. (2014) examined physical and

1 - Physical Performance \& Athletic Research Center, Faculty of Sports Science, Pablo de Olavide University, Spain.

2 - Faculty of Sports Science, Pablo de Olavide University, Seville, Spain. 
physiological variables in adult handball players during $30 \mathrm{~min}$ of a simulated game using GPS technology. In addition, Luteberget and Spencer (2017) used wearable inertial measurement unit (IMU) technology to produce high-intensity activity profiles in international female handball matches. These kinds of descriptive studies may be useful because they provide better knowledge of physical and physiological demands that handball players face during training and competition.

With regard to the analysis of demands that competition places on handball players, studies carried out using time-motion analysis have focused mainly on total distance traveled, total sprint distance, changes in activity during the game and jumping activity as external load indicators, while the percentage of the maximal heart rate $\left(\mathrm{HR}_{\max }\right)$ has been assessed as an internal load indicator (Bělka et al., 2014; Michalsik and Aagaard, 2015; Michalsik et al., 2013, 2014; Šbila et al., 2004). Manchado et al. (2013) reported on acceleration changes without threshold detection, measured via time-motion analysis. Chelly et al. (2011) analyzed the total displacements made by adolescent handball players in 6 matches of 25 min each half (1.777 $\mathrm{m}$ per match) and the distances covered while sprinting (faster than 25 $\mathrm{km} \cdot \mathrm{h}^{-1}: 98.2 \mathrm{~m}$ ) and at high intensity (between 18.1 - $24.9 \mathrm{~km} \cdot \mathrm{h}^{-1}: 173.3 \mathrm{~m}$ ), finding significant differences between the first and second halves. The heart rate (HR) over the whole match ranged between $65-85 \%$ of $\mathrm{HR}_{\max }$ for $\sim 65 \%$ of the match time and exceeded $85 \%$ of $\mathrm{HR}_{\max }$ for $\sim 15 \%$ of the match time (Chelly et al., 2011).

Luteberget and Spencer (2017) found that studies on handball tasks performed at high intensity did not consider all accelerations or high-intensity actions that occur at low speed. However, this question is very important for the quantification of high-intensity actions, since acceleration requires large amounts of metabolic energy even if performed at low speeds (Osgnach et al., 2010). In order to determine the demands on athletes in team sports, repeated acceleration sequences (RAS) are another element to consider, as has been shown in several studies of different team sports during competition situations (Aughey, 2011; Barberó-Álvarez et al., 2014; Suarez-Arrones et al., 2016).

Despite a growing research interest in measuring physical and physiological demands using GPS technology in a range of team sports, including soccer and rugby union, to the best of our knowledge, no studies have used GPS technology to analyze and compare the physical and physiological demands during the first and second halves of handball matches, involving young players, and no handball study has divided each half into smaller periods to determine specific demands. This could be important to discover when the demands of the match increase and when they decrease. Therefore, the aim of the present study was twofold: (a) to describe the physical and physiological demands of two handball matches in adolescent male players, and (b) to compare movement analysis and exercise intensities between the first and second halves and in different periods of the match.

\section{Methods}

\section{Participants}

Fourteen male adolescent handball players (age: $15.7 \pm 0.8$ years, body height: $169.5 \pm$ $3.9 \mathrm{~cm}$, body mass: $65.6 \pm 3.4 \mathrm{~kg}$ ) volunteered to participate in this study. The handball players belonged to two academy squads in the same handball club. Activity analysis was performed with twelve field handball players, since the goalkeepers were excluded. All players participated in an average of 5 hours a week of specific training plus a weekly competition game. The players had an average of $8.0 \pm 0.3$ years of handball experience. Written consent was obtained from the participants' parents/guardians after they had been thoroughly informed of the purpose, testing procedures and potential risks of the study. Approval for the study was obtained from the Ethics Committee of the Pablo de Olavide University and the study conformed to the Declaration of Helsinki.

\section{Design}

An observational design was used to analyze the activity profile of players during two friendly matches. GPS, accelerometer and HR data were used to provide quantitative information on match play (type and distribution of locomotive activities and exercise intensity). The matches were played on an outdoor field using handball regulations for $2 \times 30$ min without "time-out" and with a 10-min rest period between halves. Each team was composed of six field 
players and one goalkeeper. Player changes were not allowed, thus all players played the full match. The weather was warm $\left(\sim 20^{\circ} \mathrm{C}\right)$ during the match, with moderate humidity $(\sim 50 \%)$. Before the matches, a 20-min standardized warm-up was performed, which incorporated continuous running and displacement, followed by joint mobility. Then, explosive exercises were performed, such as strides, changes of direction and skipping. A short break was provided to hydrate and then specific technical tasks were carried out.

\section{Match-play analysis}

Running-demands data registered included total distance covered (TD), distance covered at velocities faster than $18 \mathrm{~km} \cdot \mathrm{h}^{-1}$ (TDC $>18 \mathrm{~km} \cdot \mathrm{h}^{-1}$ ), total accelerations (Accel) and decelerations (Decel), number of accelerations and decelerations greater than $2.78 \mathrm{~m} \cdot \mathrm{s}^{-2}$ (Accel $>2.78$ $\mathrm{m} \cdot \mathrm{s}^{-2}$ and Decel $>2.78 \mathrm{~m} \cdot \mathrm{s}^{-2}$, respectively), number of sprints (Sprints) and repetition of maximal accelerations separated by a maximum of $30 \mathrm{~s}$ (Suarez-Arrones et al., 2016). A sprint was defined as at least $1 \mathrm{~s}$ at $>20 \mathrm{~km} \cdot \mathrm{h}^{-1}$ (Suarez-Arrones et al., 2016). These variables were similar to those previously reported in other sports using GPS technology (Arruda et al., 2015; Aughey, 2011; Corvino et al., 2014; Suarez-Arrones et al., 2016).

Each player wore a GPS unit (SPI Pro X; GPSports Systems, Canberra, Australia) during the match. The GPS unit was placed on the upper back between the shoulders of each player, inside an adjustable neoprene vest. The GPS data were collected at a frequency of $15 \mathrm{~Hz}$, and the accelerometer data at $100 \mathrm{~Hz}$. The validity and reliability of the GPS system have been previously reported to measure acceleration and high intensity displacement in team sports (Coutts and Duffield, 2010; Varley et al., 2012). Polar Team HR monitors with short-range telemetry (SPI Pro X, GPSports Systems, Canberra, Australia) were used to measure HR during the entire game. HR zones were relativized to the $\mathrm{HR}_{\max }$ of players during the matches. Three zones of HR were established: $<65 \%, 65-85 \%$, and $>85 \%$ of $\mathrm{HR}_{\max }$ ( $\mathrm{HR}_{<65 \%}, \mathrm{HR}_{65-85 \%}$ and $\mathrm{HR}_{>85 \%} \%$, respectively) for identifying the percentage of playing time spent in each intensity zone (Chelly et al., 2011). The mean HR (HRmean) was also measured. All variables were analyzed by comparing the first and second halves and each 10-min period (P1: 0 to $10 \mathrm{~min}$; P2: 10 to $20 \mathrm{~min}$; P3: 20 to $30 \mathrm{~min}$; P4: 30 to $40 \mathrm{~min}$; P5: 40 to $50 \mathrm{~min}$; P6: 50 to $60 \mathrm{~min}$ ). Field players' data were collected from two friendly matches ( $\mathrm{n}=24$ files from 12 different players). All data were analyzed with software designed for measuring the physical demands of the match (Team AMS R1 2013.9, Canberra, Australia).

\section{Statistical Analysis}

Values are reported as mean \pm standard deviation (SD). The level of significance was set at $p \leq 0.05$. The distribution of each variable was examined using the Shapiro-Wilk normality test. Homogeneity of variance was verified using the Levene's test. To assess the differences between the first and second halves, data were analyzed using a paired samples t-test. To compare the differences between the 10-min time periods, data were analyzed using repeated measures (P1 vs. P2 vs. P3 vs. P4 vs. P5 vs. P6) analysis of variance (ANOVA), with Bonferroni post hoc adjustments. A non-parametric test (Wilcoxon test) was performed for those variables that did not display a normal distribution. Effect sizes (ESs) were calculated using Hedge's $g$ on the pooled SD (Hedges and Olkin, 2016) and 90\% confidence limits (CL) were calculated for all dependent variables. Pearson's correlation coefficients (r) and 95\% CL were calculated to establish the respective relationships between physical and physiological variables during each half. ESs were calculated using a purpose-built spreadsheet. The remaining statistical analyses were performed using SPSS software version 21.0 (SPSS Inc., Chicago, IL).

\section{Results}

Differences between match halves

The differences in running demands between the first and second halves are shown in Table 1. Greater TD $(p<0.001$; ES: -1.22$)$ and TDC $>18 \mathrm{~km} \cdot \mathrm{h}^{-1}(p=0.003$; ES: -0.31$)$ were attained during the first half compared to the second half. Moreover, more sprints were performed by each player during the first half ( $p<0.001$; ES: -0.64$)$. Both Accel and Decel also showed a decrease in the second compared to the first half $(p=0.011$ and 0.001; ES: -1.01 and -0.79 , respectively), while Accel $>2.78 \mathrm{~m} \cdot \mathrm{s}^{-2}$ and Decel $>2.78 \mathrm{~m} \cdot \mathrm{s}^{-2}$ did not show significant differences between halves (ES: -0.27 and 0.00 , respectively). In addition, lower RAS $\leq 30$ s were reported during the second compared to the first half ( $p=0.003$; ES: -0.45$)$. 
Table 2 presents the differences in HR levels between each half. A lower $\mathrm{HR}_{\text {mean }}$ was observed in the second compared to the first half ( $p=0.001$; ES: -0.55$)$. In terms of the percentage of time that players spent in each HR zone, no significant differences were found in $\operatorname{HR}_{<65 \% \max }(p=$ 0.86; ES: -0.07$)$ and $\mathrm{HR}_{>85 \% \max }(p=0.06$; ES: -0.49$)$, while HR65-85\%max showed a significant increase in the second compared to the first half $(p=0.045$; ES: 0.56).
Relationships between game variables during each match half

The relationships between different game variables are shown in Table 3. No significant relationships were observed between any of the physical variables and the $\mathrm{HR}_{\text {mean }}$ attained by handball players in each match half. In general, significant relationships were observed between all physical variables analyzed, except Decel with TDC $>18 \mathrm{~km} \cdot \mathrm{h}^{-1}$ and Sprints (in both halves). In addition, no significant relationships were observed between Accel and RAS $\leq 30$ s during the first half.

Table 1.

Running performance and repeated high-intensity activities during each half in adolescent handball players.

\begin{tabular}{cccccc}
\hline Variables & First Half & Second Half & $p$ & $\Delta \mathbf{~ ( \% )}$ & SD $\mathbf{~ 9 0 \% ~ C L ) ~}$ \\
\hline TD $(\mathrm{m})$ & $2394.2 \pm 215.0$ & $2128.7 \pm 202.0$ & $<0.001$ & -11.9 & $-1.22 \pm 0.21$ \\
TDC $>18 \mathrm{~km} \cdot \mathrm{h}^{-1}(\mathrm{~m})$ & $126.8 \pm 93.0$ & $94.1 \pm 56.3$ & 0.003 & -25.8 & $-0.31 \pm 0.18$ \\
Accel $(\mathrm{n})$ & $45.2 \pm 8.9$ & $35.9 \pm 9.8$ & $<0.001$ & -20.6 & $-1.01 \pm 0.31$ \\
Accel $>2.78 \mathrm{~m} \cdot \mathrm{s}^{-2}(\mathrm{n})$ & $5.6 \pm 4.1$ & $4.2 \pm 3.6$ & 0.016 & -25.0 & $-0.27 \pm 0.24$ \\
Decel $(\mathrm{n})$ & $55.9 \pm 11.7$ & $47.1 \pm 12.8$ & 0.001 & -15.7 & $-0.79 \pm 0.25$ \\
Decel $>2.78 \mathrm{~m} \cdot \mathrm{s}^{-2}(\mathrm{n})$ & $4.8 \pm 2.1$ & $4.7 \pm 2.8$ & 0.276 & -2.1 & $0.00 \pm 0.30$ \\
Sprints $(\mathrm{n})$ & $31.1 \pm 8.9$ & $24.9 \pm 7.6$ & 0.011 & -19.9 & $-0.64 \pm 0.30$ \\
RAS $\leq 30 \mathrm{~s}(\mathrm{n})$ & $11.1 \pm 5.5$ & $8.1 \pm 5.1$ & 0.003 & -27.0 & $-0.45 \pm 0.35$ \\
\hline
\end{tabular}

p-values indicate significant differences between halves TD: Total distance covered;

TDC $>18 \mathrm{~km} \cdot \mathrm{h}^{-1}$ : Distance covered at velocities faster than $18 \mathrm{~km} \cdot \mathrm{h}^{-1} ;$ Accel: number of

accelerations; Accel $>2.78 \mathrm{~m} \cdot \mathrm{s}^{-2}:$ number of accelerations higher than $2.78 \mathrm{~m} \cdot \mathrm{s}^{-2}$;

Decel: number of decelerations; Decel $>2.78 \mathrm{~m} \cdot \mathrm{s}^{-2}$ : number of decelerations higher than $2.78 \mathrm{~m} \cdot \mathrm{s}^{-2}$;

Sprints: number of sprints; $R A S \leq 30$ s: repetition of accelerations interspersed with a maximum

of $30 \mathrm{~s}$ between them; $\Delta$ : percentage of change of the different variables between the first and second halves; SD: Standardized differences;

$$
\text { CL: Confidence Limit. }
$$

Table 2.

Heart rate values and percentages of playing time spent at each exercise intensity zone during each half in adolescents handball players.

\begin{tabular}{cccccc}
\hline Variables & First Half & Second Half & $p$ & $\Delta(\%)$ & SD (90\% CL) \\
\hline HRmean $(b p m)$ & $169.1 \pm 8.9$ & $163.1 \pm 7.2$ & 0.001 & -3.5 & $-0.55 \pm 0.31$ \\
HR $65 \%(\%)$ & $3.1 \pm 1.4$ & $3.1 \pm 2.0$ & 0.860 & 0.0 & $-0.07 \pm 0.69$ \\
HR $65-85 \%(\%)$ & $53.9 \pm 24.2$ & $67.6 \pm 19.4$ & 0.045 & 25.4 & $0.56 \pm 0.44$ \\
HR $>85 \%(\%)$ & $42.9 \pm 26.2$ & $29.2 \pm 20.1$ & 0.060 & -31.9 & $-0.49 \pm 0.42$ \\
\hline
\end{tabular}

p-values indicate significant differences between halves $H R_{m e a n}$ : Mean heart rate;

$H R_{<65 \%}$ : Percentage of playing time spent below $65 \%$ of the maximal heart rate;

HR65-85\%: Percentage of playing time spent between 65 - 85\% of the maximal heart rate;

$H R>85 \%$ : Percentage of playing time spent above $85 \%$ of the maximal heart rate; $\Delta$ : percentage of change of the different variables between the first and second halves; SD: Standardized differences; CL: Confidence Limit. 
Table 3.

Matrix of relationships between physical and physiological variables during first half and second half.

\begin{tabular}{|c|c|c|c|c|c|c|c|c|}
\hline FIRST HALF & $\begin{array}{l}\mathrm{TDC}>18 \mathrm{~km} \cdot \mathrm{h}^{-1} \\
(\mathrm{~m})\end{array}$ & Accel (n) & $\begin{array}{c}\text { Accel }>2.78 \mathrm{~m} \cdot \mathrm{s}^{-2} \\
(\mathrm{n})\end{array}$ & Decel (n) & $\begin{array}{c}\text { Decel }>2.78 \mathrm{~m} \cdot \mathrm{s}^{-2} \\
(\mathrm{n})\end{array}$ & Sprints (n) & RAS $\leq 30 s$ (n) & $\begin{array}{l}\text { HRmean } \\
\text { (bpm) }\end{array}$ \\
\hline $\mathrm{TD}(\mathrm{m})$ & $\begin{array}{c}0.72^{* * *} \\
(0.50 \text { to } 0.85)\end{array}$ & $\begin{array}{c}0.64^{* *} \\
(0.38 \text { to } 0.81)\end{array}$ & $\begin{array}{c}0.51^{*} \\
(0.20 \text { to } 0.73)\end{array}$ & $\begin{array}{c}0.51^{*} \\
(0.20 \text { to } 0.73)\end{array}$ & $\begin{array}{c}0.62^{* *} \\
(0.35 \text { to } 0.79)\end{array}$ & $\begin{array}{c}0.72^{* * *} \\
(0.50 \text { to } 0.85)\end{array}$ & $\begin{array}{c}0.49^{*} \\
(0.18 \text { to } 0.71)\end{array}$ & $\begin{array}{c}0.29 \\
(-0.06 \text { to } 0.58)\end{array}$ \\
\hline $\begin{array}{l}\text { TDC }>18 \mathrm{~km} \cdot \mathrm{h}^{-1} \\
\quad(\mathrm{~m})\end{array}$ & & $\begin{array}{c}0.53^{* *} \\
(0.23 \text { to } 0.74)\end{array}$ & $\begin{array}{c}0.58^{* *} \\
(0.29 \text { to } 0.77)\end{array}$ & $\begin{array}{c}0.36 \\
(0.02 \text { to } 0.63)\end{array}$ & $\begin{array}{c}0.52^{* *} \\
(0.21 \text { to } 0.73)\end{array}$ & $\begin{array}{c}0.90^{* * *} \\
(0.81 \text { to } 0,95)\end{array}$ & $\begin{array}{c}0.78^{* *} \\
(0.60 \text { to } 0.89)\end{array}$ & $\begin{array}{c}0.21 \\
(-0.14 \text { to } 0.52)\end{array}$ \\
\hline $\begin{array}{c}\text { Accel }>2.78 \mathrm{~m} \cdot \mathrm{s}^{-2} \\
\text { (n) }\end{array}$ & & & & $\begin{array}{c}0.62^{* *} \\
(0.35 \text { to } 0.79)\end{array}$ & $\begin{array}{c}0.64^{* *} \\
(0.38 \text { to } 0.81)\end{array}$ & $\begin{array}{c}0.67^{* *} \\
(0.42 \text { to } 0.82)\end{array}$ & $\begin{array}{c}0.70^{* * *} \\
(0.47 \text { to } 0.84)\end{array}$ & $\begin{array}{c}0.20 \\
(-0.15 \text { to } 0.51)\end{array}$ \\
\hline Decel (n) & & & & & $\begin{array}{c}0.77^{* * *} \\
(0.58 \text { to } 0.88)\end{array}$ & $\begin{array}{c}0.38 \\
(0.04 \text { to } 0.64)\end{array}$ & $\begin{array}{c}0.22 \\
(-0.13 \text { to } 0.52)\end{array}$ & $\begin{array}{c}-0.01 \\
(-0.35 \text { to } 0.34)\end{array}$ \\
\hline
\end{tabular}

Decel $>2.78 \mathrm{~m} \cdot \mathrm{s}^{-2}$

(n)

$\begin{array}{ccc}0.54^{* *} & 0.51^{*} & 0.09 \\ (0.24 \text { to } 0.75) & (0.20 \text { to } 0.73) & (-0.26 \text { to } 0.42)\end{array}$

Sprints (n)

$0.77^{* * *} \quad 0.39$

(0.58 to 0.88$)$ (0.05 to 0.65$)$

RAS $\leq 30$ s (n)

0.12

$(-0.23$ to 0.45$)$

\begin{tabular}{|c|c|c|c|c|c|c|c|c|}
\hline $\begin{array}{l}\text { SECOND } \\
\text { HALF }\end{array}$ & $\begin{array}{c}\mathrm{TDC}>18 \mathrm{~km} \cdot \mathrm{h}^{-1} \\
(\mathrm{~m})\end{array}$ & Accel (n) & $\begin{array}{c}\text { Accel }>2.78 \mathrm{~m} \cdot \mathrm{s}^{-} \\
2(\mathrm{n})\end{array}$ & Decel (n) & $\begin{array}{c}\text { Decel }>2.78 \mathrm{~m} \cdot \mathrm{s}^{-2} \\
\text { (n) }\end{array}$ & Sprints (n) & RAS $\leq 30 s$ (n) & $\begin{array}{l}\text { HRmean } \\
\text { (bpm) }\end{array}$ \\
\hline $\mathrm{TD}(\mathrm{m})$ & $\begin{array}{c}0.80^{\text {****}} \\
(0.63 \text { to } 0.90)\end{array}$ & $\begin{array}{c}0.66^{* * *} \\
(0.41 \text { to } 0.82)\end{array}$ & $\begin{array}{c}0.60^{* *} \\
(0.32 \text { to } 0.78)\end{array}$ & $\begin{array}{c}0.51^{*} \\
(0.20 \text { to } 0.73)\end{array}$ & $\begin{array}{c}0.54^{* *} \\
(0.24 \text { to } 0.75)\end{array}$ & $\begin{array}{c}0.66^{* * *} \\
(0.41 \text { to } 0.82)\end{array}$ & $\begin{array}{c}0.52^{* *} \\
(0.21 \text { to } 0.73)\end{array}$ & $\begin{array}{c}0.30 \\
(-0.05 \text { to } 0.58)\end{array}$ \\
\hline $\begin{array}{l}\text { TDC }>18 \mathrm{~km} \cdot \mathrm{h}^{-1} \\
(\mathrm{~m})\end{array}$ & & $\begin{array}{c}0.63^{* *} \\
(0.36 \text { to } 0.8)\end{array}$ & $\begin{array}{c}0.70^{* * *} \\
(0.47 \text { to } 0.84)\end{array}$ & $\begin{array}{c}0.39 \\
(0.05 \text { to } 0.65)\end{array}$ & $\begin{array}{c}0.58^{* *} \\
(0.29 \text { to } 0.77)\end{array}$ & $\begin{array}{c}0.91^{* * *} \\
(0.82 \text { to } 0.96)\end{array}$ & $\begin{array}{c}0.68^{* *} \\
(0.44 \text { to } 0.83)\end{array}$ & $\begin{array}{c}0.19 \\
(-0.17 \text { to } 0.50)\end{array}$ \\
\hline
\end{tabular}

Accel (n)

$\begin{array}{llllll}0.57^{* * *} & 0.89^{* * *} & 0.86^{* * *} & 0.45^{*} & 0.56^{* *} & 0.16\end{array}$

Accel $>2.78 \mathrm{~m} \cdot \mathrm{s}^{-2}$

(n) $(0.28$ to 0.76$) \quad(0.79$ to 0.94$) \quad(0.73$ to 0.93$) \quad(0.13$ to 0.69$) \quad(0.27$ to 0.76$) \quad(-0.20$ to 0.48$)$

$\operatorname{Decel}(n)$

$0.58^{* *}$

$0.74^{* * *}$

$0.68^{* * *} \quad 0.62^{* *} \quad 0.06$

(0.29 to 0.77$) \quad(0.53$ to 0.86$) \quad(0.44$ to 0.83$) \quad(0.35$ to 0.79$) \quad(-0.29$ to 0.40$)$

Decel (n)

$0.88^{* * *}$

$0.24 \quad 0.44^{*}$

0.03

Decel $>2.78 \mathrm{~m} \cdot \mathrm{s}^{-2}$

(n)

(-0.11 to 0.54$) \quad$ (0.11 to 0.68$) \quad(-0.32$ to 0.37$)$

Sprints (n)

$\begin{array}{ccc}0.44^{*} & 0.61^{* *} & -0.01 \\ (0.11 \text { to } 0.68) & (0.34 \text { to } 0.79) & (-0.35 \text { to } 0.34)\end{array}$

Sprints (n)

$0.48^{*} \quad 0.11$

(0.16 to 0.71$) \quad(-0.24$ to 0.44$)$

0.11

RAS $\leq 30$ s (n)

$(-0.24$ to 0.44$)$

Data are presented as Pearson correlation coefficients and 95\% of confidence intervals (in parenthesis). TD:

Total distance covered; TDC $>18 \mathrm{~km} \cdot \mathrm{h}^{-1}$ : Distance covered at velocities faster than $18 \mathrm{~km} \cdot \mathrm{h}^{-1}$;

Accel: number of accelerations; Accel $>2.78 \mathrm{~m} \cdot \mathrm{s}^{-2}:$ number of accelerations higher than $2.78 \mathrm{~m} \cdot \mathrm{s}^{-2}$;

Decel: number of decelerations; Decel $>2.78 \mathrm{~m} \cdot \mathrm{s}^{-2}:$ number of decelerations higher than $2.78 \mathrm{~m} \cdot \mathrm{s}^{-2}$;

Sprints: number of sprints; RAS $\leq 30$ s: repetition of accelerations interspersed with a maximum

of 30 s in-between; HRmean: Mean heart rate. ${ }^{*}$ Denotes significance at $P \leq 0.05 ;{ }^{* *}$ Denotes significance at $p$ $\leq 0.01$. ${ }^{* *}$ Denotes significance at $p \leq 0.001$ 


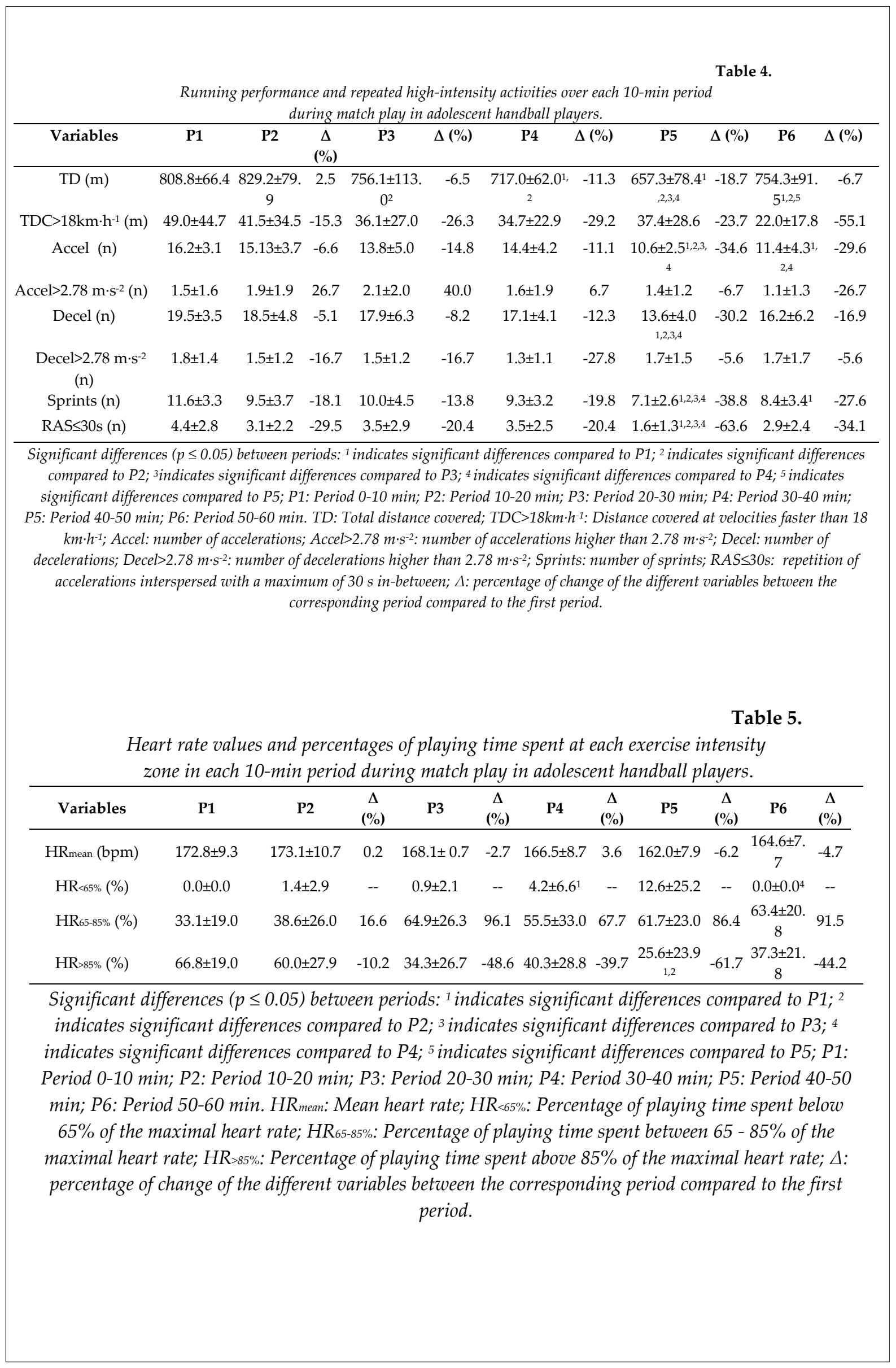


Differences between 10-min periods

Table 4 shows a comparison of running performance and repeated high-intensity activities between the 10-min periods considered. No significant differences were observed between the first two periods (P1 and P2) for any of the variables analyzed. Players covered a lower TD during P3 than during P2 $(p=0.001)$. In addition, a lower TD was covered during P4 compared to P1 and P2 $(p<0.001)$. During P5 there were lower values for TD, Accel, Decel, Sprints, and RAS $\leq 30 \mathrm{~s}$ compared to the previous periods (P1, P2, P3 and P4). During P6, a lower TD was covered than during $\mathrm{P} 1$ and $\mathrm{P} 2$, but TD was higher than during P5. In addition, lower Accel values were observed during P6 compared to P1, P2 and P4. Lastly, during P1 more Sprints were performed than during P6.

Table 5 shows HR values and percentages of playing time spent at each exercise intensity zone in each 10-min period during match play. No significant differences were observed for HRmean and HR65-85\%max between periods. During P4, players spent more time at $\mathrm{HR}_{665 \%}$ than during P1 and P6. In addition, players spent less time at $\mathrm{HR}>85 \% \max$ during $\mathrm{P} 5$ than during $\mathrm{P} 1$ and $\mathrm{P} 2$.

\section{Discussion}

This study analyzed the match-play activity profile for adolescent handball players, using GPS and HR monitoring to compare the first and the second half of the matches and to compare between 10-min periods throughout each match. To the best of our knowledge, no studies have analyzed match-play activity in adolescent handball players using GPS technology. Thus, the data obtained will be discussed in relation to studies that used other types of tools for evaluation (time-motion analysis through video analysis and IMU devices). Exercise intensity assessed by both time-motion and HR data decreased as the matches progressed.

The results of the present study show that adolescent handball players covered higher distances than those previously reported by Chelly et al. (2010) in video analysis of elite adolescent handball players, who traveled a TD of $1777 \pm 264 \mathrm{~m}$ in matches of $2 \times 25 \mathrm{~min}$ and where player changes were allowed. However, in the present study matches were played using handball regulations for $2 \times 30 \mathrm{~min}$, but player changes were not allowed, in order to compare time-motion and HR data behavior throughout the match. These reasons could explain the higher distances observed in the present study. Nevertheless, Póvoas et al. (2012) reported similar TDs to those observed in the present study in elite adult handball using video analysis, where players covered TD of $4370 \pm 702 \mathrm{~m}$ in official matches. However, the fact that these studies used video analysis and player changes were allowed may hamper direct comparison between the studies. Another objective of the present study was to determine whether players' running performance remained constant throughout the duration of the match. The present data revealed that there was a significant decrease in TD during the second half. Similarly, Chelly et al. (2010) also reported a decrease in TD during the second half of the game. Regarding the differences between the 10-min periods, the results showed significant differences between periods, highlighting that players covered less TD as the match went on. Greater distances were covered during the first two periods $(0-20 \mathrm{~min})$ in comparison to the rest of the game. However, no significant differences were observed between the last ten minutes of the first half and the last ten minutes of the game (50$60 \mathrm{~min}$ ), suggesting that the players were able to finish the second half with a similar running performance to that achieved at the end of the first half (Table 4). This may be due to the fact that these last minutes may be critical for the final outcome, thus, although fatigue has been developing during the match, players are trying to maintain their performance until the end of the game. This is the first study to examine the matchplay activity profile during handball matches comparing different 10 -min periods.

High-intensity running and sprinting may be very important during a handball match, because such actions may be decisive for the final game outcome. The present study shows that the distance covered at high intensity (TDC $>18 \mathrm{~km} \cdot \mathrm{h}^{-1}$ ) was significantly lower in the second compared to the first half. Chelly et al. (2010) also reported significant differences in distance covered at high intensity between halves by adolescent handball players, as did Póvoas et al. (2012). Regarding the 10 -min periods, no significant differences were observed between periods, although a tendency 
towards a decrease in physical and physiological performance as the match went on was observed. The small sample size is a limitation of this study. Future studies incorporating larger sample sizes and multiple matches will help in defining the match-play activity profile in handball players.

In regard to the number of accelerations and decelerations performed during the entire handball game, a significant decrease was observed from the first to the second half for both variables. It was not possible to compare our results with those of other studies, since, to our knowledge, no published research has examined the ranges of acceleration and deceleration in youth handball players. Regarding the 10-min periods, lower Accel values were observed at the end of the match (P5 and P6) in comparison to the beginning of both halves (P1, P2 and P4). This may indicate an accumulation of fatigue at the end of the match, which may be reflected by a decrease in the number of accelerations performed. Similar behavior was observed for Decel, since lower Decel was observed during P5 with respect to the previous periods (P1, P2, P3 and P4). Finally, no significant differences were observed for Accel $>2.78 \mathrm{~m} \cdot \mathrm{s}^{-2}$ and Decel $>2.78 \mathrm{~m} \cdot \mathrm{s}^{-2}$ between any time periods throughout the game. Although these data cannot be compared with other handball studies, they coincide with studies carried out in rugby sevens (Suarez-Arrones et al., 2016) and Rugby Union (Jones et al., 2015), in which no significant differences were found during the match for these two variables.

Analyzing the number of sprints performed, this study shows differences between halves, which is in agreement with Chelly et al. (2011), who also found a decrease in sprints performed during the second compared to the first half for adolescent handball players. However, in other studies carried out with elite players, no significant differences were found in sprints performed during each half (Póvoas et al., 2012, 2014b). Moreover, Michalsik et al. (2014) did not find differences in the number of sprints performed during each half of a match when studying elite female handball players. Comparisons with previous studies are difficult because of the analysis systems (video analysis) and different speed thresholds used to classify high-intensity running actions as sprints. In line with the rest of high-intensity actions analyzed, fewer Sprints were observed at the end of the match (P5) in comparison to the previous 10-min periods (P1, P2, P3 and P4), which seems to indicate an unintentional decrease in highintensity actions as fatigue develops during a handball match.

In handball, the ability to repeat high intensity actions is a very important variable (Karcher and Buchheit, 2014). This variable involves the repetition of sequences of maximum accelerations (RAS) and has been defined as two maximum accelerations $\left(>2.78 \mathrm{~m} \cdot \mathrm{s}^{-2}\right)$ with a recovery time shorter than $\leq 30 \mathrm{~s}$ (Suarez-Arrones et al., 2014). Adolescent handball players who participated in this study showed impairment in RAS performance from the first to the second half. Additionally, lower RAS were observed at the end of the match (P5) with respect to the previous 10min periods (P1, P2, P3 and P4). These findings are in line with those observed for the rest of the high-intensity actions analyzed in the present study. Although no studies have previously analyzed this variable in handball, previous research has found that the frequency of the appearance of tasks of an explosive character, such as changes of direction, $1 \times 1$ situations or jumps, is lower in the second compared to the first half (Karcher and Buchheit, 2014; Michalsik et al., 2014; Póvoas et al., 2012, 2014b). In other sports, such as rugby-sevens, Suarez-Arrones et al. (2016) showed a reduction of $25.8 \%$ in RAS between halves.

HR variables have usually been used as internal load indicators (Bělka et al., 2014; Michalsik and Aagaard, 2015; Póvoas et al., 2012; Suarez-Arrones et al., 2014;). In the present study, the HRmean was higher during the first compared to the second half of a game in adolescent handball players, which agrees with the data obtained from elite adult handball players (Póvoas et al., 2012) and from elite adolescent handball players (Chelly et al., 2011). No significant differences were observed for HRmean between any 10-min periods. In contrast, Póvoas et al. (2014b) found that the last periods of matches showed significant differences with respect to the first periods, although in this case the intervals were 5 -min periods. On the other hand, no significant differences were observed between the first and the second half in the time spent in both the lowest $\left(\mathrm{HR}_{<65 \%}\right)$ and the highest 
(HR $\left.{ }_{85} \%\right)$ zones, while in the intermediate zone (HR65-85\%max), there was a significant increase in the second half compared to the first half. Our results are partially in agreement with previous studies, since Chelly et al. (2011) did not observe significant differences in any HR zones between halves in elite adolescent handball players, whereas Povoas et al. (2012, 2014a) reported significant differences between halves in moderate and high intensity zones in elite adult players. However, these studies used different thresholds to determine the time spent in each HR zone (Póvoas et al., 2012, 2014a). In order to analyse cardiovascular demands throughout the match, we also assessed the time spent in each HR zone in particular 10-min periods. At the beginning of the second half (P4), less time was spent at $\mathrm{HR}_{<65 \%}$ compared to $\mathrm{P} 1$ and $\mathrm{P} 6$, which may indicate that during the break between halves, players reduced their HRmean because of the inactivity associated with that period. No significant differences were found in $\mathrm{HR}_{65-85 \%}$ between any 10-min periods. Lastly, during P5, less time was spent at $\mathrm{HR}_{>85 \%}$ compared to the first two 10-min periods (P1 and P2). This may indicate that accumulated fatigue throughout the first five periods caused a decrease in players' performance, as can be observed in high-intensity actions (Table 4) carried out during this period.

Assessment of mechanical (i.e., running demands) and physiological (i.e., HR responses) demands imposed during a handball match is the first step in the design of specific conditioning programs. Adolescent handball players showed lower levels of performance in the second half of matches, especially in the middle of this period. Additionally, these time-motion variables are related to themselves, mainly high-intensity related variables, as can be observed in Table 3 .
These relationships show that players that performed a higher number of sprints were also those that covered longer high-intensity distances and performed a higher number of maximal accelerations and decelerations. Collectively, these findings provide important information for the prescription of training aimed at developing physiological qualities specific to the demands of handball players and physical fitness testing adapted to these requirements. In order to attenuate the decrement in exercise intensity observed throughout the entire handball game and improve performance variables, such as sprint and acceleration capacities, proper resistance training programs should be implemented in young handball players (Marques and González-Badillo, 2006; Marques, 2010). Additionally, the possibility offered by handball official rules to make unlimited player changes during matches is a fundamental tool that coaches must consider in the programming of games to avoid the accumulation of fatigue in players. Future research should include the analysis of a greater number of handball matches with teams of different ages, gender and performance levels.

\section{Conclusions}

During a handball game, players must be physically prepared for continuous ball throwing, jumps, sprints and changes of direction. However, impairment in performance throughout the entire game was observed in adolescent handball players. Additionally, greater intensity impairment was observed in the middle of the second half (P5) in comparison to the previous 10min periods (P1, P2, P3 and P4). Taken together, these findings indicate that there is an unintentional decrease in high-intensity actions as fatigue develops during a handball match.

\section{References}

Arruda AFS, Carling C, Zanetti V, Aoki MS, Coutts AJ, Moreira A. Effects of a very congested match schedule on body-load impacts, accelerations, and running measures in youth soccer players. Int J Sports Physiol Perform, 2015; 10: 248-252

Aughey RJ. Increased high-intensity activity in elite Australian football finals matches. Int J Sports Physiol Perform, 2011; 6: 367-379

Barberó-Álvarez JC, Boullosa D, Nakamura FY, Andrín G, Weston M. Repeated Acceleration Ability (RAA): A New Concept with Reference to Top-Level Field and Assistant Soccer Referees. Asian J Sports Med, 2014; 5: 63-66 
Barbero JC, Granda-Vera J, Calleja-González J, Del Coso J. Physical and physiological demands of elite team handball players. Int J Perform Anal Sport, 2014; 14: 921-933

Bělka J, Hulka K, Safar M, Weisser R, Samcova A. Analyses of Time-Motion and Heart Rate in Elite Female Players (U19) during Competitive Handball Matches. Kinesiology, 2014; 46: 33-43

Chelly MS, Hermassi S, Aouadi R, Khalifa R, Van den Tillaar R, Chamari K, Shephard RJ. Match analysis of elite adolescent team handball players. J Strength Cond Res, 2011; 25: 2410-2417

Chelly MS, Hermassi S, Shephard RJ. Relationships between Power and Strength of the Upper and Lower Limb Muscles and Throwing Velocity in Male Handball Players. J Strength Cond Res, 2010; 24: 14801487

Corvino M, Tessitore A, Minganti C, Sibila M. Effect of Court Dimensions on Players' External and Internal Load during Small-Sided Handball Games. J Sports Sci Med, 2014; 13: 297-303

Coutts AJ, Duffield R. Validity and reliability of GPS devices for measuring movement demands of team sports. J Sci Med Sport, 2010; 13: 133-135

Gorostiaga EM, Izquierdo M, Iturralde P, Ruesta M, Ibáñez J. Effects of heavy resistance training on maximal and explosive force production, endurance and serum hormones in adolescent handball players. Eur J Appl Physiol Occup Physiol, 1999; 80: 485-493

Granados C, Izquierdo M, Ibáñez J, Ruesta M, Gorostiaga EM. Effects of an entire season on physical fitness in elite female handball players. Med Sci Sports Exerc, 2008; 40: 351-61

Hedges L V., Olkin I. Overlap between treatment and control distributions as an effect size measure in experiments. Psychol Methods, 2016; 21: 61-68

Jones MR, West DJ, Crewther BT, Cook CJ, Kilduff LP. Quantifying positional and temporal movement patterns in professional rugby union using global positioning system. Eur J Sport Sci, 2015; 15: 488-96

Karcher C, Buchheit M. On-Court Demands of Elite Handball, with Special Reference to Playing Positions. Sport Med, 2014; 44: 797-814

Luteberget LS, Spencer M. High-Intensity Events in International Women's Team Handball Matches. Int J Sports Physiol Perform, 2017; 12: 56-61

Manchado C, Pers J, Navarro F, Han A, Sung E, Platen P. Time-motion analysis in women's team handball: Importance of aerobic performance. J Hum Sport Exerc, 2013; 8: 376-390

Marques MC. In-Season Strength and Power Training for Professional Male Team Handball Players. Strength Cond J, 2010; 32: 74-81

Marques MC, González-Badillo JJ. In-season resistance training and detraining in professional team handball players. J Strength Cond Res, 2006; 20: 563-571

Michalsik LB, Aagaard P. Physical demands in elite team handball: comparisons between male and female players. J Sports Med Phys Fitness, 2015; 55: 878-91

Michalsik LB, Madsen K, Aagaard P. Match performance and physiological capacity of female elite team handball players. Int J Sports Med, 2014; 35: 595-607

Michalsik LBB, Aagaard P, Madsen K. Locomotion characteristics and match-induced impairments in physical performance in male elite team handball players. Int J Sports Med, 2013; 34: 590-599

Ortega-Becerra M, Pareja-Blanco F, Jiménez-Reyes P, Cuadrado-Peñafiel V, González-Badillo JJ. Determinant Factors of Physical Performance and Specific Throwing in Handball Players of Different Ages. J Strength Cond Res, 2018; 32: 1778-1786

Osgnach C, Poser S, Bernardini R, Rinaldo R, di Prampero PE. Energy cost and metabolic power in elite soccer: a new match analysis approach. Med Sci Sports Exerc, 2010; 42: 170-178

Póvoas S, Ascensão A, Magalhães J, Seabra A, Krustrup P, Soares J, Rebelo A. Analysis of fatigue development during elite male handball matches. J Strength Cond Res, 2014a; 28: 2640-2648

Póvoas S, Seabra A, Ascensão A, Magalhães J, Soares J, Rebelo A. Physical and Physiological Demands of Elite Team Handball. J Strength Cond Res, 2012; 26: 3365-3375

Póvoas S, Ascensaõ A, Magalhães J, Seabra A, Krustrup P, Soares J, Rebelo A. Physiological demands of elite team handball with special reference to playing position. J Strength Cond Res, 2014b; 28: 430-442

Šbila M, Vuleta D, Pori P. Position-related differences in volume and intensity of large-scale cyclic movements of male players in handball. Kinesiol Int J Fundam Appl Kinesiol, 2004; 36: 58-68 
Suarez-Arrones L, Arenas C, López G, Requena B, Terrill O, Mendez-Villanueva A. Positional differences in match running performance and physical collisions in men rugby sevens. Int J Sports Physiol Perform, 2014; 9: 316-23

Suarez-Arrones L, Núñez J, Sáez de Villareal E, Gálvez J, Suarez-Sanchez G, Munguía-Izquierdo D. Repeated-High-Intensity-Running Activity and Internal Training Load of Elite Rugby Sevens Players During International Matches: A Comparison Between Halves. Int J Sports Physiol Perform, 2016; 11: 495-499

Taylor JB, Wright AA, Dischiavi SL, Townsend MA, Marmon AR. Activity Demands During MultiDirectional Team Sports: A Systematic Review. Sports Med, 2017

Varley MC, Fairweather IH, Aughey RJ. Validity and reliability of GPS for measuring instantaneous velocity during acceleration, deceleration, and constant motion. J Sports Sci, 2012; 30: 121-127

\section{Corresponding author:}

\section{Manuel Ortega-Becerra.}

Physical Performance \& Athletic Research Center, Faculty of Sport,

Pablo de Olavide University, Seville,

Spain Ctra. de Utrera, km 141013 Seville, Spain.

E-mail: maortbec@upo.es 